\title{
USEFULNESS OF ADENOSINE DEAMINASE LEVELS IN THE DIAGNOSIS OF PLEURAL EFFUSIONS
}

\author{
N. Vijaya Bhaskar Reddy¹, G. Sundar Raj², P. Yugandhar 3 , S. Satya Sri ${ }^{4}$ \\ ${ }^{1}$ Ex-Junior Resident, Department of Pulmonary Medicine, Asram Medical College, Eluru, Andhra Pradesh. \\ ${ }^{2}$ Associate Professor, Department of Pulmonary Medicine, Asram Medical College, Eluru, Andhra Pradesh. \\ 3 Professor, Department of Pulmonary Medicine, Asram Medical College, Eluru, Andhra Pradesh. \\ ${ }_{4}$ Professor \& HOD, Department of Pulmonary Medicine, Asram Medical College, Eluru, Andhra Pradesh.
}

\begin{abstract}
Adenosine deaminase activity was estimated in 75 patients of pleural effusions of different etiologies. Patients were classified into three groups Tuberculosis (55), malignant (10) transudates (7), purulent effusion (3), based on diagnosis made on fluid examination and other investigations. The diagnosis was made independent of ADA activity. Out of 55 cases of tuberculous pleural effusions 54 have ADA activity of $>40$ IU/1 Mean ADA activity in Tuberculous pleural effusions is significantly higher (66.41 \pm 29.31 ) than that of malignant pleural effusions $(p<0.001)$. Mean ADA activity in malignant pleural effusions $(17.32 \pm 2.641)$ is significantly higher than that of Transudative pleural effusions $(11 \pm 3.12)(p<0.001)$. ADA activity has no relation to the radiological extent of effusion and sputum status for AFB. There is no significant difference in ADA activity between males and females. All malignant pleural effusions have mean ADA levels less than $40 \mathrm{IU} / 1$. The sensitivity, specificity and positive predictive values obtained for tuberculous pleural effusions in the present study are 98.8\%, 100\%., 100\% respectively (taking 40 IU/1 as a cut off limit to discern tuberculous from non-tuberculous effusions). The results of the present study confirm that the ADA activity in pleural fluid is a very good parameter for the differential diagnosis of pleural effusions, compared to the conventional tests. ADA estimation is simple, low cost and least invasive and should be considered in the routine study of pleural effusions, particularly if diagnosis of tuberculosis is contemplated and in places where prevalence of this disease is still high.
\end{abstract}

KEYWORDS: ADA - Adenosine Deaminase - PLEF - Pleural Effusions.

HOW TO CITE THIS ARTICLE: N. Vijaya Bhaskar Reddy, G. Sundar Raj, P. Yugandhar, S. Satya Sri. "Usefulness of Adenosine Deaminase Levels in the Diagnosis of Pleural Effusions". Journal of Evolution of Medical and Dental Sciences 2015; Vol. 4, Issue 88, November 02; Page: 15336-15339, DOI: 10.14260/jemds/2015/2181.

INTRODUCTION: Pleural effusion is not a disease on its own. It is a manifestation of various underlying disorders that includes respiratory, renal, cardiovascular, connective tissue and other diseases. The pleural cavity is more frequently perceived for its vices, such as pleural effusion, than for its physiologic function mainly because it is vulnerable to and shows alterations in many cardiopulmonary and other diseases. The clinical recognition of pleural effusion signals and abnormal pathophysiologic state that has resulted in disequilibrium between pleural Fluid formation and removal. Pleural effusions are frequent and constitute difficult diagnostic problems in clinical practice. Even though detecting pleural effusion is an easy thing diagnosis of the actual disease underlying the pleural effusion pose' great diagnostic challenge in a considerable number of cases. In spite of careful diagnostic evaluation etiology of the effusion can't be established in about $20 \%$ of the cases. The treatment in such cases has been largely empirical.

Traditionally the effusions are divided into exudates and transudate based on Lights criteria. ${ }^{1}$ If the effusion is a transudates no further diagnostic procedures on the pleural fluid are indicated and in the majority of cases the underlying cause can be diagnosed clinically.

Financial or Other, Competing Interest: None.

Submission 08-10-2015, Peer Review 09-10-2015,

Acceptance 20-10-2015, Published 31-10-2015.

Corresponding Author:

Dr. N. Vijaya Bhaskar Reddy,

D. No. G1 16-6-31, Near Vijaya Hall Gate,

Swarna Jeja Residency, Nellore City, Andhra Pradesh.

E-mail:dr.nvbreddy@gmail.com

DOI:10.14260/jemds/2015/2181
However, if the effusions are exudates, more investigations will be needed to define the cause of the pleural disease. Numerous tests are available for determining the cause of exudates, and every test has got its own limitations.

Even in expert hands, pleural biopsy gives $50-80 \%$ results with its own attendant complications, as it is invasive. In the light of these observations, Adenosine deaminase assay has been found to be simple and useful investigation in the diagnosis of pleural effusion by many studies particularly in differentiating tuberculous and malignant effusions the two most common causes from each other and from other causes of pleural exudates.

Hence this study of ADA activity in pleural effusion is undertaken to evaluate the efficiency \& utility of this test in the differential diagnosis of pleural effusions..

MATERIALS AND METHODS: A total number of 75 consecutive patients in the age group of 10-75 years who were admitted in Tuberculosis and Chest Diseases ASRAM Hospital Eluru, with the initial diagnosis of pleural effusion from July 2008 to October 2010 were taken into the present study.

Patients in age group 10-75 with following Symptom:

1. Cough with expectoration.

2. Chest Pain.

3. Fever.

4. Loss of Appetite.

5. Lost of weight.

\section{Investigations:}

- $\quad$ Chest Roentgengram (PA View, lateral View).

- Sputum smear for AFB. 
- Biochemical Analysis of Pleuralfluid

- Cellcytology

- Ultrasound Chest

Each case was diagnosed independent of ADA activity. According to the final diagnosis arrived at by the above diagnostic parameters cases were divided into 4 groups.

\section{Group I. Tuberculous Effusion \\ - Sputum - ve \\ - Sputum +ve \\ Group II Malignant Effusion \\ - Cvtology of Pleural Fluid \\ - Pleural biopsy \\ Group III Transudative Effusion \\ - CHF Cirrhosis \\ - Nephrotic syndrome \\ Group IV Purulant Effusion (Empyema) \\ - Gross appearances of the pleural fluid \\ - Biochemical analysis}

ADA activity was assessed by Galanti and Guisti's Colorimetric Method: ${ }^{2}$

RESULTS: Out of the total number of 75 cases of pleural effusions 60 are males and 15 are females, the male female ration being $4: 1$. Among the 60 males, 55 belong to tuberculosis, 10 to malignant and 7 to Transudative, 3 to purulent effusion. Out of the 15 females the figures of tuberculosis and malignant effusions are 11 and 3 respectively. Altogether there is male predominance, which is statistically significant (P less than 0.001).

The patients are in the age group of 10-75 years. The mean age in tuberculosis effusions $30 \pm 13.8$ whereas in malignancy it is $51.15 \pm 11.56$; in Transudative it is $48.15 \pm 6.92$; in purulent effusion (empyaema) is $38 \pm 9.87$. The mean age in malignant effusions IS significantly high compared to tuberculous effusions $(\mathrm{P}<0.001)$ (Table. 1) Out of 75 cases of pleural effusion 67 are unilateral and 8 are bilateral. Among the 67 unilateral effusions, 49 are on the right side and 18 are left sided.

Unilateral effusions comprise of 21 minimal, 33 moderate and 13 massive effusions. Most of the tuberculous effusions fall in moderate effusions group while majority of the malignant effusions are massive.

The mean ADA level in tuberculosis pleural effusion is $66.41 \pm 29.31$. In malignant effusion it is $17.32 \pm 2.64$, where as in Transudative effusions it is $11 \pm 3.12$, purulent effusion it is $32 \pm 8.12$.

The mean ADA activity in tuberculous pleural effusion is significantly high when compared to malignant and Transudative effusions $(\mathrm{P}<0.001)$. The mean ADA activity in malignant effusion is significantly higher than the Transudative effusion $(\mathrm{P}<0.001)$ (Table 2)

Out of the 55 cases of tuberculous pleural effusions, 54 have ADA activity more than 40 IU/1 and all the malignant and Transudative effusions have ADA level less than $40 \mathrm{IU} / 1$. Basing on the data we have taken $40 \mathrm{IU} / 1$ as cut off point in differentiating tuberculous and nontuberculous effusions with a sensitivity of $98.8 \%$ specificity $100 \%$ and positive predictive value of $100 \%$ each for tuberculous effusions.
Out of 55 cases of tuberculous pleural effusions, 14 were diagnosed by the demonstration of AFB in the sputum smear. But ADA value of more than $40 \mathrm{IU} / 1$ is found in 54 out of 55 tuberculous effusions (Table 4).

On analysis the diagnostic efficacy of sputum smear for AFB in our series is $25.4 \%$. But the efficacy of ADA is found to be $98.8 \%$ proclaiming its superiority to other diagnostic modalities in the diagnosis of tuberculous pleural effusions.

As already mentioned in 14 cases of tuberculous effusions, sputum for AFB is positive by smear.

The mean ADA activity in positive smear cases is $62.22 \pm$ 14.39 whereas in smear negative cases it is $69.33 \pm 22.58$. Though the ADA activity among the smear negative group is apparently higher than that of smear positive group, the difference is not statistically significant $(\mathrm{P}>0.05)$. So ADA activity has no relation to the bacteriological status.

10 cases of malignant pleural effusions, diagnosed on the basis of pleural fluid malignant cytology.

Among the 7 transudative effusions, congestive heart failure account for 5 cases (4 hypertention and Congestive heart failure), 2 are cirrhosis of the liver \& 1 is Nephrotic syndrome. Congestive cardiac failure \& Nephrotic syndrome was diagnosed by clinicoradiological evaluation. Cirrhosis of the liver was diagnosed by clinical finding.

DISCUSSION: Pleural effusions are divided into transudates and exudates based on Light's criteria. Transudates do not require further diagnostic procedures on the pleural fluid, since in the majority of cases the underlying cause is diagnosed clinically. However, if the effusion is exudates more investigations will be needed to define the cause of the pleural disease. Adenosine deaminase assay useful as it is simple, dependable and less expensive useful one among the numerous tests available for determining the cause of exudates. In the present study, the usefulness of ADA assay in the diagnosis of pleural effusions was evaluated by determining ADA levels in pleural fluid. Previous studies have confirmed the usefulness of ADA assay in the diagnosis of pleural exudates particularly in differentiating tuberculosis and malignant effusions.

In the present study 75 cases of pleural effusion were evaluated in detail for the diagnostic significance of Adenosine deaminase assay.

The mean age (in years) of patients with tuberculous effusions is $30.7 \pm 13.82$, while that of malignant effusions is $51.15 \pm 11.56$. The age incidence in the present study is well in agreement with those of Kraft (1949), Roper and waring (1955), Deshmukh et.al (1968), Deshmukh and virdi (1972) and Guptal et al (1988).

It was seen from table (1) that the majority of the patients in this study are males. 60 cases were males and 15 cases were females. The sex incidence noted in this series matched with those of Deshmukh et al (1968), and Deshmukh and Virdi (1972).

Malignant effusions in the present series showed a mean ADA activity of $17.32 \pm 2.64$, which is more or less similar to the results reported by the previous authors.

The mean ADA levels transudates in the present study are $17.32 \pm 2.64$, conforming with the majority of the other series. Tuberculosis and Malignant effusions had a significantly higher mean ADA levels when compared to transudates. 
The mean ADA levels observed in various studies and the present study proper may be explained by the sample size, epidemiological variations in the CMI and technical discrepancies in the procedure.

The cut off levels of ADA activity in tuberculosis effusions has been different in different studies. Inma Ocana et al found that none of their patients with tuberculous effusions had ADA activity less than $45 \mathrm{IU} / \mathrm{L}$. An arbitrary value of $40 \mathrm{IU} / \mathrm{L}$ for ADA in pleural fluid chosen by Maritz et al, $7 \%$ of tuberculous patients had a value below this value.

So, in patients with ADA activity less than $40 \mathrm{IU} / \mathrm{L}$ tuberculosis is unlikely. With values between 40 and $60 \mathrm{IU} / \mathrm{L}$ the likelihood of T.B. increase, values above $60 \mathrm{IU} / \mathrm{L}$ especially more than 80 IU/L make the diagnosis of tuberculous effusions certain.

Baldev Raj et al chose a cut off value of $40 \mathrm{IU} / 1$ and suggested that low values less than $40 \mathrm{IU} / \mathrm{L}$ serve to exclude tuberculosis and suggest the probability of malignant effusion. None of the patients in tuberculosis had values below $40 \mathrm{IU} / 1$. So ADA values below $40 \mathrm{IU} / \mathrm{L}$ make tuberculosis unlikely.

Gilhotra et al chose an arbitrary ADA value of 40 IU/1 as cut of point to differentiate tuberculous and nontuberculous effusions. All the tuberculous effusions in their series had ADA activity more than $40 \mathrm{IU} / 1$. Basing on these observations, they proposed that effusions with ADA activity more than $40 \mathrm{IU} / 1$ suggests the tuberculous etiology and effusions with ADA levels less than 40 IU/L practically excludes the diagnosis of tuberculosis.

P.K. Sinha et al considered 30 IU/L of ADA as a cutoff point and suggests that valve below $30 \mathrm{IU} / \mathrm{L}$ excludes the diagnosis of tuberculosis as a cause of effusion.

Radhav et al in their small study sample of 25 cases took a cutoff point of $25 \mathrm{IU} / \mathrm{L}$ and observed 3 cases of tuberculous effusion to fall below this level. They attributed this to the suggestive concealed history of anti tuberculous treatment. None of the malignant effusions had values above $25 \mathrm{IU} / \mathrm{L}$. In the present series on statistical analysis of the data, differentiating value of $40 \mathrm{IU} / \mathrm{L}$ of ADA activity was considered as a cutoff point in discreting tuberculosis and non-tuberculous pleural effusions. Except one case, all the tuberculous pleural effusions had an ADA value of more then $40 \mathrm{IU} / \mathrm{L}$.

None of the malignant pleural effusions exceeded this cut off limit of ADA - (40 IU/L). The probable reasons for the low level of ADA (<40 IU/L) in one case of tuberculous effusion may be multifactorial like:

- Concealed history of treatment

- Technical error

- Contamination of the pleural fluid sample

- Improper storage and transport of the sample

- $\quad$ Failure to maintain the phosphate buffer $\mathrm{pH}$ at 6.5

Regarding the fixing up of cutoff point, there are no universal standards. Cell mediated immunity varies from on geographical area to another area of the country as evidenced by the variable mantoux induration size to be considered as significant. So also the cutoff point of ADA varies because it is an indirect marker of cell mediated immunity. So we are under the opinion that many more studies are needed in this direction.

Previous authors observed ADA values in rheumatoid and Lupus effusions to be high making it difficult to differentiate them from tuberculous effusions, as there was an overlap.

As we did not encounter such cases, our comments are reserved about these observations. However, only $2-3 \%$ of patients with rheumatoid arthritis and S.L.E. have pleural effusions when compared to the magnitude of tuberculous effusions in India.

Coming to the utility of the test, basing on our data with a cut off value of (ADA) 401IU/1, we have obtained sensitivity of $98.8 \%$ specificity $100 \%$ and positive predictive values of $100 \%$ each for the diagnosis of tuberculous pleuraleffusion which is will agreement with other studies.

Baldevraj et al., at cut off point of $40 \mathrm{IU} / \mathrm{I}$ achieved a sensitivity and specificity of $100 \%$ each. Gilhotra et al 9 with a cutoff point of $40 \mathrm{IU} / \mathrm{I}$ obtained sensitivity, specificity and positive predictive values of $100 \%, 91 \%$ and $88.2 \%$ respectively.

Maritz et al obtained a sensitivity of $100 \%$ choosing a cut off value of $40 \mathrm{IU} / \mathrm{I}$. Inma Ocaria et al got a sensitivity of $100 \%$ and specificity of $97 \%$ at a cutoff point of $45 \mathrm{IU} / \mathrm{I}$. The sensitivity and specificity obtained by Vidal et. al 15 are $98 \%$ and $97 \%$ respectively (cut off limit $45 \mathrm{IU} / \mathrm{I}$ ).

Piras et al., and P.K. Sinha et al., with a cut off value of ADA at $30 \mathrm{IU} / \mathrm{I}$ reported a sensitivity and specificity of $100 \%$. The above studies and the present study clearly indicate that the ADA is highly sensitive and specific for the diagnosis of tuberculous pleural effusions.

R. Vidal et al reported a sensitivity of $98 \%$ with ADA compared to combined sensitivity of pleural biopsy and bacteriology (pleural fluid and sputum). Which was $87 \%$ in the diagnosis of tuberculuous effusions. P.K. Sinha et al obtained a diagnostic sensitivity of $100 \%$ with ADA compared to $55 \%$ with pleural biopsy, $4.54 \%$ sputum smear, $9.09 \%$ with pleural tissue Mycobacterial culture in the diagnosis of tuberculuous effusions.

These results undoubtedly emphasize the superiority of ADA over the conventional diagnostic modalities.

As per our observations, ADA activity has no relation to the radiological extent or to the bacteriological status. Jhamaria et al., also found no statistically significant difference of serum ADA activity among sputum positive and sputum negative pulmonary tuberculosis patients.

Why ADA is increased only in tuberculous effusions is not known. But this can possibly explained by the following observations made by previous workers.

ADA concentrations are increased in typhoid fever and tuberculosis in which host defenses are mostly a function of cell mediated immunity, underlying the importance of this enzyme to rapid proliferating cells and agrees well with the negative response observed in combined Immuno Deficiency syndromes. The increased enzymatic activity in tuberculous pleurisy further supports the view of a casual relationship between ADA and Tcell response. Cellular activation could be responsible for an augmented enzymatic activity to avoid accumulation of toxic metabolities, bu an increased demand for energy might be the explanation. In human pathology B cell activation seems not to be responsible for the same phenomenon.

Previous studies have shown that the percentage of Tlymphocyte sub-population in peripheral blood. Inma Ocana et al found a high percentage of T-lymphocytes in tuberculous effusions, but this was not correlated with the enzyme activity has been shown to increase substantially during mitogenic and antigenic responses of lymphocytes.

Tom Petterson et al suggested that the higher ADA activity in pleural fluid may probably due to ADA being locally synthesized by cells within the pleural cavity in tuberculosis. 
The high activity of T-lymphocyte in tuberculous effusion seems a reflection of local activation of $\mathrm{T}$ lymphocytes, a local cellular immune response.

\section{BIBLIOGRAPHY:}

1. Light R W, Macgregor MI, Luchsinger Pc, Ball We. Pleural effusions.

2. Guisti G,Galanti B,Calorimetric method,In:Bergameye HU Editor, 3rd ed. Berlin:Germany Verlag chemie, Weinheim, 1984.pp.315-323.

\begin{tabular}{|c|c|c|c|c|}
\hline Type of Plef & No. & M & F & $\begin{array}{c}\text { Age in Years } \\
\text { (X } \pm \text { SD) }\end{array}$ \\
\hline Tuberculosis & 55 & 45 & 10 & $30 \pm 13.82$ \\
\hline Malignant & 10 & 7 & 3 & $51.15 \pm 11.56$ \\
\hline Transudative & 7 & 6 & 1 & $48.15 \pm 6.92$ \\
\hline Purulent Effusion (Empyama) & 3 & 2 & 1 & $38 \pm 9.87$ \\
\hline \multicolumn{5}{|c|}{ Table 1 } \\
\hline \multicolumn{4}{|c|}{} \\
\hline \multicolumn{4}{|c|}{} \\
\hline
\end{tabular}

- $\quad$ Males Predominant $-\mathrm{P}<0.001$ S.S (CHISQUARE TEST)

- MEAN AGE IN MALIGNANT EFFUSION IS SIGNIFICANTLY HIGH P,0.001 SS (STUDENT t TEST)

\begin{tabular}{|c|c|c|}
\hline YPE OF PLEF & NO. & $\begin{array}{c}\text { ADA ACTIVITY (IU/I) } \\
\text { (X } \pm \text { SD) }\end{array}$ \\
\hline TUBERCULOSIS & 55 & $66.41 \pm 29.31$ \\
\hline MALIGNANCY & 10 & $17.32 \pm 2.64$ \\
\hline TRANSUDATIVE & 7 & $11 \pm 3.12$ \\
\hline PURULENT EFFUSION (EMPYAEMA) & 3 & $32 \pm 8.12$ \\
\hline \multicolumn{2}{|c|}{ Table 2: Pleural Fluid Ada Activity } \\
\hline
\end{tabular}

- MEAN ADA ACTIVITY IN TUPERCULOUS PLEURAL EFFUSION IS SIGNIFICANTLY HIGH COMPARED TO MALIGNANT PLEURAL EFFUSION (P,0.001 S.S STUDENT t TEST)

- MEAN ADA ACTIVITY IN MALIGNANT PLEURAL EFFUSION IS SIGNIFICANTLY HIGH COMPARED TO TRANSUDATES (P,0.001 S.S STUDENT t TEST)

UTILITY OF ADA IN TUBERCULOUS PLEURA EFFUSION CUT OFF VALUE > 40IU/I

\begin{tabular}{|c|c|}
\hline SENSITIVITY & $\mathbf{9 8 . 8}$ \\
\hline SPECIFICITY & 100 \\
\hline PREDICTIVE VALUE & 100 \\
\hline
\end{tabular}

CUT OFF VALUE < 40IU/I

\begin{tabular}{|c|c|}
\hline +VE PREDICTIVE VALUE & 5.9 \\
\hline - VE PREDICTIVE VALUE & 93.4 \\
\hline \multicolumn{2}{|c|}{ Table 3 } \\
\hline
\end{tabular}

- $\quad$ HIGHLY SENSITIVE AND SPECIFIC FOR THE DIAGNOSIS OF TUBERCULOUS PLEURAL EFFUSION

DIAGNOSTIC METHODS OF TUBERCULOUS PLEURAL EFFUSION

\begin{tabular}{|c|c|c|c|}
\hline METHOD & DONE & POSITIVE & EFFICACY \\
\hline SPUTUM FOR AFB & 55 & 14 & $25.4 \%$ \\
\hline $\begin{array}{c}\text { PLEURAL FLUID } \\
\text { ADA }\end{array}$ & 55 & 54 & $98.18 \%$ \\
\hline \multicolumn{4}{|c|}{ Table 4 } \\
\hline
\end{tabular}

ADA IS SUPERIOR TO THE OTHER METHODS FOR THE DIAGNOSIS OF TUBERCULOUS PLEURAL EFFUSION. 